\title{
Aspectos da representação dos imigrantes haitianos no jornal Gazeta do Povo, de Curitiba/PR
}

\author{
Myrian Regina Del Vecchio de Lima \\ Doutora; Universidade Federal do Paraná \\ myriandel@gmail.com
}

\section{Otávio Cezarini Ávila}

Mestre; Universidade Federal do Paraná

ota_cez@hotmail.com

\section{Andrea Rosendo da Silva}

Mestranda; Universidade Federal do Paraná

dearosendo@gmail.com

\section{Resumo}

Desde o terremoto de 2010 no Haiti, iniciou-se um fluxo constante de imigração de habitantes do país para o Brasil. Este artigo contempla a análise de matérias publicadas pelo jornal Gazeta do Povo, de Curitiba, PR, sobre a imigração dos haitianos no primeiro semestre de 2014. A escolha da temática se justifica por conta do número considerável destes imigrantes em Curitiba, bem como pelas implicações e contribuições que a investigação pode oferecer para a área de comunicação diante de um cenário global de imigração. O trabalho tem como objetivo fazer uma reflexão sobre a problemática, a identidade dos grupos envolvidos e a comunicação na esfera das migrações e partiu do pressuposto de que a mídia impressa, como forma ainda fundamental de comunicação nas sociedades democráticas, enfatiza o imigrante muito menos como ser cultural, portador de identidade e em busca de cidadania em seus percursos de deslocamento em novos territórios, e muito mais como sujeito apenas econômico. Empiricamente, realizou-se a análise de conteúdo de matérias publicadas para se compreender alguns aspectos da representação construída sobre os haitianos.

\section{Palavras-chave}

Comunicação e migração. Migração de haitianos. Cultura e cidadania. Jornal Gazeta do Povo. 


\section{Introdução}

Em janeiro de 2012, os então ministros da Justiça, José Eduardo Cardozo, e das Relações Exteriores, Antonio de Aguiar Patriota, assinaram artigo, publicado no jornal Folha de São Paulo, intitulado "Brasil e Haiti: parceria para o desenvolvimento". O texto lembrava o terremoto ocorrido no Haiti em 2010, que vitimou mais de 300 mil pessoas; mencionava a missão de paz liderada pelo Brasil; e destacava a implantação de medidas de ordenação do fluxo migratório de haitianos para o Brasil, de modo a garantir o respeito à dignidade e aos direitos humanos dos migrantes. As novas medidas contavam com o apoio do governo haitiano e das instâncias relevantes das Nações Unidas em temas migratórios.

Erra quem vê na nova medida uma restrição à entrada de haitianos no Brasil. Pelo contrário, trata-se de uma abertura, em caráter excepcional, que estabeleceu condições especiais de ingresso no Brasil, para além da liberdade de ingresso já permitida [...] 0 Brasil está cooperando com as autoridades dos países vizinhos no aprimoramento do controle e da fiscalização das fronteiras, com o objetivo de repreender as redes de intermediários. (CARDOZO; PATRIOTA, 2012, doc. não paginado).

Mais de três anos após essas declarações, vê-se que aumentou muito a imigração dos haitianos para o país. Em maio de 2014, um blog dedicado à migração haitiana no Brasil reproduziu matéria do jornal $O$ Estado de Minas, com a chamada "Brasil terá 50 mil imigrantes haitianos até o fim do ano" (MAAKAROUN; AUGUSTO, 2014). A referida matéria apresentava pesquisa, realizada entre julho e novembro de 2013, por Duval Fernandes e Maria da Consolação Castro, da PUC/MG, e pelo representante da Organização Internacional para as Migrações (OIM), que traçou o perfil da imigração haitiana ao Brasil. A pesquisa revelou que existiam naquela data no país cerca de 34 mil haitianos e que o número subiria para 50 mil até o fim de 2014, como de fato aconteceu. Os imigrantes haitianos estavam então presentes em 286 cidades, com 75\% concentrados em São Paulo.

Na reportagem, Fernandes explicou que o Brasil não é mais o país de imigração do início do século nem o país da emigração dos anos 1980: “Somos hoje um país de imigração, emigração e trânsito, além dos brasileiros que retornam depois de viver muitos anos no exterior. A questão migratória é atualmente muito maior do que foi no passado." (MAAKAROUN; AUGUSTO, 2014). No Paraná, a matéria publicada pelo jornal Gazeta do Povo (MARINS, 2013) 
afirmava que viviam naquele período, na Região Metropolitana de Curitiba, cerca de 2 mil haitianos com idade entre 20 e 40 anos $^{1}$.

Ao observar o espaço que a imigração dos haitianos ocupa na imprensa brasileira e paranaense, este trabalho tem como objetivo investigar alguns aspectos da representação desses imigrantes, construídos pelas matérias publicadas no jornal Gazeta do Povo (GP) no primeiro semestre de 2014. No entanto, para compreender porque esse tema é recorrente nos jornais, foi preciso fazer uma reflexão acerca da questão da migração, analisada sob o enfoque do jornalismo da mídia hegemônica tradicional (a GP é um jornal impresso de grande circulação regional), mas atrelada a reflexões sobre cultura e economia, baseadas em Hall (2012, 2006), Canclíni (2013), Cogo (2001, 2010, 2014) e outros autores. Cabe aqui esclarecer a ideia de cultura adotada, que neste caso abarca o conceito de territorialidade como aspecto fundamental para a migração, e ambas abarcando a concepção de cidadania, como define Santos (2012).

Desta forma, a pesquisa busca verificar alguns aspectos da representação construída pelo jornal impresso Gazeta do Povo acerca dos imigrantes haitianos residentes no Brasil, sendo que duas questões são centrais: o haitiano residente no Brasil é visto pelo jornal como um ser cultural, dotado de identidade e aspectos culturais marcantes? Ou, por outro lado, é visto por esta mídia, preponderantemente, como mão de obra barata? Estas questões derivam de um pressuposto: a mídia tradicional enfatiza o imigrante como sujeito meramente econômico, colocando em segundo plano este sujeito como ser cultural.

Escolheu-se como metodologia a análise de conteúdo do material publicado na editoria "Vida e Cidadania” do referido jornal - no período de janeiro a junho de 2014 - para verificar como se dá, de forma ampla, a representação desses imigrantes, uma vez que, com relação à mídia, "[...] podemos pensar nela como linguagens, que fornecem textos e representações para interpretação." (SILVERSTONE, 2005, p. 15). A escolha pela seção “Vida e Cidadania” do referido jornal ocorre por se tratar da editoria que aborda temas relacionados à cidadania, convivência e presença de identidades que se relacionam no âmbito da cidade. Outras seções

1 Segundo informação do site da Prefeitura de Curitiba, até novembro de 2014, constavam na Polícia Federal 2,5 mil registros de haitianos na capital paranaense, mas órgãos como a Assessoria de Direitos Humanos da Prefeitura de Curitiba trabalham com uma estimativa de 4 mil haitianos vivendo em Curitiba e região metropolitana. (SINE, 2014). 
também consideradas foram o "Caderno G", com enfoque em cultura, e o caderno "Economia", seguindo a temática que dá nome a esta editoria.

O entendimento sobre representação empregado neste artigo é amplo: é aquele baseado em Silverstone (2005), que compreende a representação como fenômeno ideológico que se observa nos textos produzidos por determinados segmentos e atores sociais, como no caso do jornalismo e de seus atores-produtores, os jornalistas. Neste sentido, o autor afirma que a mídia é fundamental ao projeto reflexivo da pós-modernidade: “[...] através das lentes múltiplas dos textos escritos, dos audiotextos e dos textos audiovisuais, o mundo é apresentado e representado: repetida e interminavelmente." (SILVERSTONE, 2005, p. 22), e ele prossegue salientando que é a mídia que filtra e molda realidades cotidianas “[...] por meio de suas representações singulares e múltiplas, fornecendo critérios, referências para a condução da vida diária, para a produção e a manutenção do senso comum." (SILVERSTONE, 2005, p. 20). Neste sentido, também se recorre a Maigret (2010) e a Van Dijk (2012).

\section{Migrações em um cenário de globalização acelerada}

A agência da Organização das Nações Unidas (ONU) para refugiados (Acnur) informou em 20 de junho de 2014, Dia Mundial do Refugiado, que o número de requerentes de asilo, refugiados e deslocados internos em todo o mundo ultrapassou, pela primeira vez após a Segunda Guerra Mundial, os 50 milhões de pessoas. O relatório anual "Tendências Globais" da Acnur, baseado em dados compilados pelos governos, organizações não governamentais e registros próprios, mostra que 51,2 milhões de pessoas foram deslocadas à força de seus territórios até o final de 2013 - 6 milhões a mais do que as 45,2 milhões registradas em 2012 (NÚMERO..., 2014). Os dados, publicados no site da ONU Brasil demonstram que a situação representa um grande contingente de pessoas que precisam de ajuda, com implicações para os orçamentos das nações doadoras e para a capacidade de absorção e abrigo dos países receptores.

No mesmo site, publicou-se matéria sobre a 1므 Conferência Nacional sobre Migração e Refúgio (Comigrar), realizada entre os dias 30 de maio e 1ํo de junho de 2014, em São Paulo, sob a coordenação do Ministério da Justiça e com apoio de organismos da ONU, que debateu a política migratória do país. 0 objetivo da I Comigrar foi elaborar aportes para a construção da 
Política e do Plano Nacional sobre Migração e Refúgio, pautados nos direitos humanos. Durante o evento, lançou-se o Plano de Integração aos Migrantes, que inclui compromisso dos governos federal, estadual e municipal de São Paulo em acolher a população haitiana no Brasil, principalmente nos estados que apresentam o maior número de haitianos.

Todas estas movimentações da sociedade civil, tentando aproximações com o Estado, fazem parte da busca pela cidadania que diversos atores sociais (organizações e instituições) desempenham junto aos haitianos residentes no Brasil, entendendo-se como modelo de cidadania aquele que decorre das interfaces entre cultura e territorialidade (SANTOS, 2012). Ao argumentar sobre sua afirmativa, Milton Santos diz, por exemplo, que a atribuição do saláriomínimo “[...] não pode ser estabelecida em função dos simples mandamentos da 'economia', mas da cultura." (2012, p. 17). Essa afirmação faz o autor dicotomizar a relação cidadania/economia, considerando a sociedade capitalista como cenário, o que impossibilita o modelo cívico ideal. Em troca disso, o autor traz a relação cultura/território, que possibilitaria ao "cidadão" os serviços de bens indispensáveis para a sua dignidade. Assim:

A plena realização do homem, material e imaterial, não depende da economia [...]. Ela deve resultar de um quadro de vida, material e não material, que inclua a economia e a cultura. Ambos têm que ver com o território e este não tem apenas um papel passivo, mas constitui um dado ativo. (SANTOS, 2012, p. 18).

Desta forma, Santos (2012), ao defender a cidadania como condição de convivência do homem em sociedade, advoga contra a noção de economia como variável chave para a vida coletiva.

Sob o ponto de vista dos estudos culturais a respeito do tema, é importante compreender os fluxos que trazem indivíduos dos mais diversos pontos do globo para novos espaços geográficos, de forma a refletir para além da superficialidade das causas mais óbvias, como a fuga da pobreza e a busca por melhores condições de vida em outro país. Elucidar a questão da cultura transnacional, permeando questões como as identidades e o território é fundamental para podermos pontuar o imigrante como ser cultural em um cenário global profundamente marcado pelo viés do econômico.

Ao considerar as formações identitárias que compõem o indivíduo como parte da cultura, Hall (2012) acrescenta ao debate, a partir de suas reflexões sobre a diáspora caribenha, a 
complexa situação das identidades culturais em ambientes de violação do espaço. Como a identidade se constitui historicamente, muitos povos são impedidos de dar continuidade ao seu passado, pois seus locais originários não podem ser mais os mesmos, como é o caso da capital haitiana, Porto Príncipe, destruída por um terremoto e alterada por todos os processos sociais, políticos e econômicos anteriores e subsequentes.

Não podemos jamais ir para casa, voltar à cena primária enquanto momento esquecido de nossos começos e 'autenticidade', pois há sempre algo no meio [...]. Mas cada disseminação carrega consigo a promessa do retorno redentor. (HALL, 2012, p. 30).

Com o entendimento de que é a cultura que nos dá a consciência de pertencimento e, portanto, que as migrações agrediriam o indivíduo nesta dura adaptação à nova terra, Santos (2012) relaciona desterritorialização (a perda do território original, do espaço de pertencimento e memória) à alienação, para ele, uma desculturização. Mas Santos não condena o migrante à eterna alienação - as incitações e a capacidade criativa do homem fazem com que ele não aja apenas de forma passiva, e que a relação entre o homem e o território:

[...] manifesta-se dialeticamente como territorialidade nova e cultura nova, que interferem reciprocamente mudando-se paralelamente territorialidade e cultura, mudando o homem. Quando essa síntese é percebida, o processo de alienação vai cedendo ao processo de integração e de entendimento, e o indivíduo recupera parte do seu ser que parecia perdida. (SANTOS, 2012, p. 83).

Ao mesmo tempo em que há a possibilidade de integração², Canclíni (2013) observa a existência de estratégias na tensão entre desterritorialização e reterritorialização, que dizem respeito a esta perda da relação natural da cultura com os territórios geográficos e sociais, como salienta também Santos (2012), e, ao mesmo tempo, às relocalizações territoriais relativas, parciais, das velhas e novas produções simbólicas. Há nesta trama de desterritorialização (alienação) e reterritorialização (integração) um resultado híbrido que dá forma às culturas dominadas, inclusive com o componente transcultural, que parte de uma seleção e invenção dos grupos subordinados a partir do que foi transmitido pela cultura dominante. Há aqui tra-

\footnotetext{
2 Integração, neste trabalho, refere-se à possibilidade de interação da cultura receptora com a cultura migrante, sem que esta seja assimilada pela outra. A integração, a partir da perspectiva da multiculturalidade, presente neste trabalho, compreende que as culturas, ao se encontrarem, hibridizam-se, gerando novos saberes, relações e práticas sociais, como afirma Bhabha (1998).
} 
jetórias que se entrecruzam e são dialógicas, e que, muitas vezes, sofrem as inflexões de variáveis conflitantes.

Ao se considerar que todas as culturas são resultado de mestiçagens e traduções, é necessário para que elas permaneçam - ou simplesmente não desapareçam - argumentações que mostrem a diferença desta cultura por intermédio da valorização do que lhe é próprio, realizadas pelos grupos culturais e étnicos.

Não há, no entanto, uma relação "de origem e cópia" no contato das culturas e suas diásporas (HALL, 2012, p. 38), pois as fronteiras rígidas pelas quais se acreditava que uma cultura emergiria não se adéquam ao hibridismo em que as culturas hoje estão inseridas. Esta forma preconizada pelos Estados-Nação, por intermédio de comunidades políticas nacionais e suas "comunidades imaginadas" e pelas políticas nacionalistas, é posta em desuso pelos caminhos que a globalização toma (na relação de conquista, exploração, formação de mercados mundiais, homogeneização cultural), sendo que a própria acepção das fronteiras nacionais é recusada pela sociedade, que se fragmenta internamente.

Desta forma, Hall (2012) comenta que a fase transnacional do capitalismo, pós-1970, “[...] tem seu 'centro' cultural em todo lugar e em lugar nenhum [...]” (p. 40), com as formas cada vez mais globais de mercado e fluxos do capital. E, do mesmo modo que o capital invade as zonas periféricas, também as minorias chegam ao centro, rompendo barreiras espaciais e adentrando na cultura dominante. No entanto, ainda há uma problemática nesta lógica de fluxos e hibridização cultural que justifica as migrações, cujo cenário é o da globalização de um capitalismo avançado, de interesse pautado na constituição de mercados regionais, configurando uma lógica onde é “[...] mais simples fazer investimentos em um país estranho do que se tornar cidadão." (CANCLÍNI apud COGO, 2001, p. 13).

Assim, no âmbito deste texto, que relaciona imigração e aspectos de sua representação em uma mídia jornalística, é preciso entender quais as variáveis relacionadas à constituição da comunicação neste cenário de mudanças globais, regionais e locais, que possam estar conectadas com perspectivas culturais e de cidadania no que diz respeito ao fenômeno das migrações. 


\section{Comunicação na esfera das migrações}

Embora o objeto empírico da pesquisa seja um veículo de comunicação tradicional onde se insere, em termos de conteúdo, aspectos da representação da migração haitiana no Brasil, faz-se necessário ampliar a reflexão da comunicação a respeito deste fenômeno, pois, em si, a migração já se apresenta como uma possibilidade comunicativa.

Utilizando a perspectiva da comunicação cidadã e transnacional, Denise Cogo (2010) salienta três processos de mudança. 0 primeiro está relacionado à constituição e circulação de imaginários na disputa pelos sentidos na cidadania a partir das tecnologias da informação tradicionais e online. Um segundo processo se refere à modalidade de relacionamento de redes solidárias, as quais extrapolam o espaço físico. Neste ponto, Cogo ainda trata de "redes de comunidades virtuais identitárias" em um processo de definições de identidade entre atores coletivos. 0 terceiro momento diz respeito aos movimentos migratórios que proporcionam novas relações, conflitos culturais e aprofundamento de contatos. A autora considera a interrelação entre redes sociais, tecnologias de comunicação e movimentos migratórios para compreender a dimensão transnacional da comunicação em uma perspectiva cidadã. Pode-se considerar, por meio do entendimento acima, que a mobilidade impulsionada pela globalização tem sua tensão aprofundada pelo aspecto subjetivo do indivíduo que se move. Este indivíduo híbrido carrega consigo um conjunto de contradições culturais que se expressam, de forma explícita ou implícita, em suas práticas comunicativas e maneiras de se comunicar.

Em especial, o terceiro momento citado pela autora ganha destaque neste trabalho pela natureza comunicativa da migração, considerando-se este fenômeno ser capaz de produzir interações sociocomunicativas através de sociabilidades que "[...] se desenrolam na trama das relações cotidianas tecidas em encontros nos quais os imigrantes se interpelam e se constituem como sujeitos e se afirmam na polissemia dos intercâmbios." (COGO, 2013, p. 13), sejam estas relações estabelecidas com atores individuais ou coletivos, como as instituições com as quais os haitianos têm contato em Curitiba e pelas quais a mídia tem acesso a informações sobre o fenômeno migratório em questão.

É importante também compreender a relação do uso das tecnologias de comunicação no cenário urbano globalizado, uma vez que é no espaço das cidades que se concentra o número de indivíduos migrantes, alterando estes espaços, do ponto de vista material e simbóli- 
co. Ao falar sobre o processo de urbanização, Canclíni (2013) diz que “[...] viver em uma cidade não implica dissolver-se na massa e no anonimato." (p. 286). Para ele, as novas tramas da cidade, repletas de violência e insegurança, fazem com que indivíduos busquem uma sociabilidade seletiva em seu espaço doméstico e confiável. Um ponto que contribui para a conformação do fenômeno de perda do sentido agregador da cidade é a mistura de burocratização e midiatização, resultando na redução do “[...] uso massivo da cidade para a teatralização política [...]" (CANCLÍNI, 2013, p. 287), com os meios de comunicação fazendo a mediação com a população.

A menor visibilidade das estruturas macrossociais, sua subordinação a circuitos não-materiais e diferidos de comunicação, que mediatizam as interações pessoais e grupais, é uma das causas pelas quais caiu a credibilidade dos movimentos sociais [...] (CANCLÍNI, 2013, p. 287).

Ao se ler a realidade urbana seguindo o viés de Canclíni (2013), a eficácia dos movimentos sociais dependeria de uma reorganização do espaço público em um esforço para abranger a massa. E a resposta não se daria pelas formas tradicionais de comunicação, mas pelos próprios meios massivos que conseguiriam restituir o sentido do urbano a partir da capacidade de horizontalizar/verticalizar a difusão da informação.

Se é notável a disputa pelos sentidos da cidadania a partir da reorganização do espaço público pelas formas comunicacionais, o fenômeno das migrações humanas vai sendo composto tanto pela ação das mídias convencionais quanto pelas narrativas dos próprios migrantes e suas redes que enunciam as experiências desta mobilidade, compostas por espaços midiáticos próprios - que aqui não serão explorados - como blogs, páginas no Facebook, vídeos do Youtube, etc. (COGO; BADET, 2013).

Dos três pontos já anteriormente mencionados por Cogo em relação à comunicação cidadã e transnacional, o terceiro deles proporciona novas relações, conflitos culturais e aprofundamento de contatos. Considerando que o aprofundamento das relações pode ser motivado por determinado lugar geográfico, é possível afirmar que as questões do território e os significados simbólicos são dados pela comunicação entre os habitantes originários e os sujeitos migrantes. Nesse sentido, ElHajji (2011) evidencia a natureza do espaço, ainda que de transição, interagindo com estruturas de comunicação comunitárias, em especial nos processos de reterritorialização: 


\begin{abstract}
Antes de serem, todavia, guetos estanques, essas configurações simbólico territoriais constituem espaços de encontros, trocas e misturas com o conjunto da sociedade. Na maioria dos casos, o território étnico não passa de um espaço de transição, uma interface cultural que possibilita uma integração suave e proporcional à ascensão social almejada por todo imigrante. Esforço de enraizamento e reterritorialização que, na prática comunicacional, se reflete por notáveis estruturas de comunicação e mídia comunitárias. (ELHAJJI, 2011, p. 6).
\end{abstract}

É dentro desta perspectiva comunicacional (cidadã e transnacional) que se situa a reterritorialização e a integração dos migrantes, elaboradas também por meio de novas produções simbólicas, nas quais acredita-se que se situe a localização da diferença cultural de povos deslocados forçadamente pela globalização.

Esta inserção da comunicação midiática ou interpessoal avança para a transformação cultural, levando à compreensão que a cultura é uma produção dinâmica e coletiva. "Não é uma questão do que as tradições fazem de nós, mas daquilo que fazemos das nossas tradições [...]", afirma Hall (2012, p. 49), que enfatiza também que o ser humano está sempre em processo de formação cultural, sendo que a "[...] cultura não é uma questão de ontologia, de ser, mas de se tornar." (p. 49). 0 mesmo autor assinala (2012) ainda que é necessário não se apegar a modelos fechados e homogêneos de "pertencimento cultural", mas abarcar os processos mais amplos, que transformam culturas do mundo todo. Para ele (2012), o caminho da "diáspora" é esta trajetória de um povo e de uma cultura moderna, sem, no entanto, criar zonas de silêncio, como fez o internacionalismo europeu.

\title{
4 Meios de comunicação e representação dos imigrantes: agendamento e homogeneização nas representações
}

De acordo com Eric Maigret (2010), os meios de comunicação de massa constituem a afirmação das sociedades democráticas, tornando possíveis as trocas de informações entre diferentes povos e culturas. Para o autor, pelo fato de ligarem os homens, estes meios formam culturas e participam de culturas, enquanto favorecem, sabotam ou estabilizam poderes. Os jornais, como afirma Maigret (2010), respondem às aspirações do estado de democracia (fracionamento das ideias individuais). 0 "poder" ligado aos jornais é, ao mesmo tempo, “[...] o de representar a variedade das opiniões, permitir que algumas dessas opiniões triunfem mais rapidamente, sempre enraizando um consenso." (MAIGRET, 2010, p. 58). 
Para o mesmo autor, os modelos teóricos da agenda setting e da espiral do silêncio trazem um retorno à noção de efeito, uma vez que "[...] recapitulam a evolução do pensamento sociológico, dos efeitos à construção social dos fatos, mas deslocando a reflexão para o nível macrossocial, o do confronto do conjunto dos meios de comunicação e da sociedade." (MAIGRET, 2010, p. 310):

Os efeitos dos meios de comunicação operam no nível societal e a longo prazo, não por inculcação, mas neutralizando a seletividade ou fazendo-a incidir sobre um conjunto de escolhas. Com a noção de agenda 3 , Maxwell McCombs e Donald Shaw confeccionam um instrumento original para identificar e comparar as opiniões veiculadas pelos meios de comunicação e as opiniões dos cidadãos, a fim de estabelecer os vínculos entre elas. (MAIGRET, 2010, p. $311)$.

Denise Cogo e Maria Badet (2013) afirmam que não somente os meios de comunicação de massa, mas também a conversação pública gerada pelas redes de relacionamento tem um impacto imediato em práticas como a do jornalismo, pois é capaz de refletir de modo instantâneo as narrativas sobre os acontecimentos que chamariam a atenção da imprensa convencional. Segundo as autoras, a perspectiva abordada seria o efeito do agendamento promovido por estas redes sobre a grande imprensa, mas reconhecem que o jornalismo convencional ainda é determinante:

Na perspectiva da teoria do agendamento ou agenda setting, é possível observar, alguns deslocamentos a partir de temas que emergem originalmente das redes de relacionamento, embora seja necessário reconhecer que a chancela do chamado jornalismo convencional ainda concentra o estabelecimento das pautas públicas da sociedade. (COGO; BADET, 2013, p. 43).

As pautas públicas da sociedade, bem como as representações de grupos subalternos, estão relacionadas com a estrutura do poder dos meios de comunicação. Ao dissertar sobre o controle do discurso, os modos de reprodução discursiva e a reprodução ideológica, Teun A. van Dijk (2012) destaca que, nos meios de comunicação, o controle do conhecimento é exercido por meio da seleção restritiva de assuntos e de reconstruções específicas das realidades sociais e políticas. Afirma, ainda, que esse processo é dirigido por um sistema de valores e de

\footnotetext{
3 Segundo Maigret (2010), uma agenda é "[...] uma hierarquia de prioridades, uma lista de problemas em jogo classificados por importância crescente, e que se pode apreender, por exemplo, enumerando em dado momento os assuntos tratados na imprensa e a quantidade de tempo no ar e/ou de linhas que eles geram, ou, para os cidadãos, efetuando sondagens de opinião e entrevistas. A correlação entre as agendas, estatisticamente verificadas pelos autores, ou mesmo a anterioridade das preocupações dos jornalistas conduzem a postular a pergunta da influência por efeito da estrutura." (MAIGRET, 2010, p. 311).
} 
ideologias profissionais sobre as notícias e sobre o que deve ou não ser notícia. Segundo o autor, as "elites simbólicas"4, incluindo os jornalistas, detêm relativa liberdade e poder para tomar decisões sobre os gêneros de discurso e determinar o estilo ou a forma de apresentação de um discurso.

Esse poder simbólico não se limita à articulação em si, mas também inclui o modo de influência: eles podem determinar a agenda da discussão pública, influenciar a relevância dos tópicos, controlar a quantidade e o tipo de informação, especialmente quanto a quem deve ganhar destaque publicamente e de que forma. (VAN DIJK, 2012, p. 45)

Van Dijk (2012) afirma que, ao fazer o processo seletivo das fontes de informação e dos assuntos que merecem destaque, a mídia jornalística decide quais atores serão representados na arena pública, o que será dito e como será dito a respeito deles. Ao analisar manchetes de matérias jornalísticas sobre grupos étnicos na imprensa holandesa e suas representações, o autor problematizou o papel dos jornalistas na construção dessas representações. Segundo Van Dijk (2012), os jornalistas daquele país (na maioria brancos e do sexo masculino) escrevem como representantes profissionais das instituições de comunicação e, simultaneamente, como membros do grupo dominante branco, ocidental, levando-o a concluir que essa postura molda as cognições sociais desses profissionais e, consequentemente, o processamento de informações sobre os grupos externos.

Em uma série de estudos de análise do discurso de notícias na imprensa, Van Dijk (2008) examina como os grupos sociais subordinados são representados nos textos noticiosos e verifica que há uma homogeneização nas representações, explicando que as minorias, os refugiados, os sem-teto e os países e as populações do Terceiro Mundo parecem ser representados de maneira geralmente semelhante, ou seja, em contraste com a apresentação dos grupos e países poderosos.

A conclusão geral desses estudos é a de que esses e outros grupos externos: a) tendem a ter menos acesso aos meios de comunicação de massa dominantes; b) são menos usados como fontes de noticias usuais e confiáveis; c) são descritos de forma, se não negativa, principalmente como um "problema social", se não como um fardo ou mesmo uma ameaça a nossos valiosos recursos; d) são tidos como "deficientes" ou "atrasados" de varias maneiras, quan-

\footnotetext{
4 Van Dijk (2012) explica que as "elites simbólicas", representadas por jornalistas, escritores, artistas, diretores, acadêmicos e outros grupos, exercem o poder com base no "capital simbólico" (BOURDIEU, 1977, 1984; BORDIEU; PASSERON, 1977). Para o autor, essas elites são os fabricantes do conhecimento, dos padrões morais, das crenças, das atitudes, das normas, das ideologias e dos valores públicos. Portanto, seu poder simbólico é também uma forma de poder ideológico.
} 
do comparados a nossos objetivos, normas, conhecimento ou cultura; e, portanto, (e) precisam de nossa ajuda, compreensão ou apoio (altruísta), pressupondo que se adaptem às nossas normas e ideologias sociais e políticas. (VAN DIJK, 2012, p. 75).

No entanto, para Van Dijk (2012), o poder dos meios de comunicação não deve ser compreendido em termos de "efeitos" simplistas. Embora não faça uma reflexão sobre recepção, o autor argumenta que as diferenças socioeconômicas e socioculturais interferem na forma como as pessoas interpretam, representam e avaliam as matérias jornalísticas e os eventos noticiosos e, consequentemente, em como formam opiniões, atitudes e ideologias diferentes. Nesse sentido, é importante ressaltar que os meios de comunicação são extensões das lutas e das partilhas simbólicas da sociedade, como lembra Maigret (2010): “Os meios de comunicação são espaços onde atuam a formação, a reprodução e a contestação de conjunto de práticas e de crenças, misturando indissociavelmente poder e cultura, e cada um desses elementos se lê no outro." (MAIGRET, 2010, p. 309).

É com este entendimento que, de forma ampla, analisamos alguns aspectos das representações sobre os imigrantes haitianos no jornal Gazeta do Povo.

\section{Procedimentos metodológicos}

A metodologia utilizada neste trabalho é uma simplificação da análise de conteúdo, que se revela como método de grande utilidade na pesquisa jornalística. Ao utilizar este procedimento, mesmo que de maneira genérica e não detalhista, em pesquisa ainda preliminar, partimos do seguinte questionamento: as matérias do jornal paranaense Gazeta do Povo, publicadas no período selecionado, representam o haitiano apenas como mão de obra para o mercado capitalista transnacional (uma visão hegemônica e economicista) ou como um indivíduo portador de cultura e em busca de integração cidadã em um novo território?

Fundada há 95 anos, a Gazeta do Povo pertence ao Grupo Paranaense de Comunicação (GRPCOM), o maior do Paraná na área. De janeiro a junho de 2014, o veículo publicou matérias, notas, artigos, reportagens, incluindo matéria de capa, relacionadas com os haitianos. Para verificar se o jornal representa o haitiano apenas do ponto de vista econômico, ou também o representa como sujeito cultural, realizou-se a análise do conteúdo, buscando, no con- 
junto das matérias, as abordagens relacionadas à economia e à cultura, termos que funcionaram como subtemáticas.

A pesquisa abarcou as notícias referentes ao tema imigração, mas se deteve nas imigrações haitianas devido ao elevado número de nativos do Haiti que migraram para o Brasil nos últimos quatro anos. A escolha destas duas abordagens, econômica e cultural, deu-se pelo interesse em verificar como esse sujeito em trânsito é revelado pelo viés jornalístico. A investigação realizou-se em três editorias: Vida e Cidadania; Economia e Caderno G (caderno de cultura), que reúnem matérias que demarcam os conteúdos relativos à cultura e economia, aspectos que interessam a este artigo.

Ao se levar em conta a sugestão de Herscovitz (2008) para definir os temas de análise, avançamos além da tematização jornalística, que "[...] pressupõe a seleção de um tema e sua colocação no centro da atenção pública." (ALSINA, 2009, p. 191) —, utilizando os subtemas "economia" e "cultura" como categorias de análise, como já explicitado, de forma a checar as abordagens jornalísticas; entretanto, emergiram ainda da primeira leitura do conjunto de textos outros subtemas, que podem ser considerados unidades de registro das categorias assinaladas, como "políticas nacionais" e "fluxos migratórios".

A busca para localizar o tema principal e os subtemas realizou-se, primeiramente, no jornal impresso, em 160 edições no período mencionado, encontrando-se 32 referências em seções como capa, artigos/opinião do leitor, reportagem, notas curtas, colunas, dentre outras, e 23 referências nas três editorias citadas. Na versão online da Gazeta do Povo, por uma questão de segurança metodológica, foram pesquisadas as palavras "Haiti" e "haitianos", resultando um total de 19 matérias com os termos apenas na editoria Vida e Cidadania, o que confirmou o resultado obtido no jornal impresso. Para a análise, consideraram-se apenas as 19 matérias da editoria Vida e Cidadania, que apresentou maior número de matérias sobre a tematização em exame.

\section{Análise das matérias sobre migrações na editora Vida e Cidadania}

No conjunto das matérias sobre imigrações haitianas no Brasil no período examinado, foram encontradas na editoria Vida e Cidadania 13 matérias (de um total de 19) com abordagens relacionadas à economia. Percebeu-se também que, deste universo, nove delas foram 
publicadas entre os meses de abril e maio, período em que houve intensa cobertura da mídia nacional sobre a entrada de milhares de haitianos no país pelo estado do Acre. Verificou-se que sete das nove matérias desse conjunto foram produzidas por agências de notícias de São Paulo, principal destino dos imigrantes. Percebe-se um distanciamento espacial, mas também um deslocamento do próprio indivíduo haitiano neste movimento que mobilizou a imprensa, os políticos, a igrejas e ONGs.

Isto se evidencia ao se perceber, pela leitura interpretativa do conteúdo de cada matéria, que os antecedentes que determinaram a vinda dos haitianos para o Brasil não são explorados como poderiam, especialmente ao se considerar que se tornam complexas as identidades culturais quando seus espaços originais são violados, caso do Haiti, cujas ocupações militares aliadas às catástrofes naturais e socioeconômicas corromperam o espaço original deste povo. Não há enfoques sobre as condições que antecedem a vinda dos imigrantes em nenhuma das matérias, o que demonstra um distanciamento do ser cultural dessas pessoas no que se refere à sua territorialidade. 0 texto que mais se aproxima destes antecedentes - "Pedidos de refúgio crescem quase dez vezes" (PEDIDOS..., 2014, p. 5) - ainda assim trata de maneira genérica o tema: "Os fatores que levam a isso são múltiplos [...]. Em terceiro lugar, o acirramento de alguns conflitos internacionais [...] e a inversão de fluxos migratórios." (PEDIDOS..., 2014, p. 5).

Além disso, notou-se uma ênfase de cobertura sobre os efeitos negativos que a migração causa ao país receptor. Alguns entraves causados pelos migrantes são postos em destaque já nos títulos: “Em situação precária, haitianos ‘lotam’ o Acre” (EM SITUAÇÃO..., 2014, p. 8), "São Paulo monta plano emergencial para atender haitianos" (SÃO PAULO..., 2014, p. 4). "Secretário diz que haitianos estão sendo ‘despejados' na cidade” (SECRETÁRIO..., 2014, p. 9) e "Acordo dá conta bancária para haitianos em São Paulo" (ACORDO..., 2014, p. 7) 0 tratamento do migrante como um problema, evidenciado nestas matérias, vem de encontro ao que Van Dijk (2012) também encontrou em pesquisa na imprensa holandesa, constituindo uma negação à própria dinâmica imposta pela sociedade capitalista, ao se levar em conta que as fronteiras nacionais são negadas pela sociedade (representada pelo Estado), enquanto, globalmente, acordos permitem a abertura irrestrita de mercados, com repercussão sobre aspectos da cultura e da cidadania. 
Apesar da procura das empresas brasileiras por trabalhadores haitianos, apenas uma notícia com este foco foi encontrada na editoria de Economia da Gazeta do Povo neste período: "Haitianos reclamam direitos trabalhistas" (CARDOSO; SENKOVSKI, 2014, p. 21). Isso não significou que matérias relacionadas à questão empregatícia tenham sido deixadas de lado: pelo contrário, recorrentemente o tema foi encontrado na editoria Vida e Cidadania, inclusive com uma matéria curta, relatando a burocracia para obtenção da carteira de trabalho para haitianos (ACORDO..., 2014, p. 7), além de uma matéria sobre trabalho escravo, associada mais aos bolivianos: (LACHINI, 2014, p. 7) e ao racismo no ambiente de trabalho (HAITIANOS..., 2014, p. 5).

Assim, a questão do trabalho parece emergir mais pelo viés da busca pela cidadania do que pelo viés econômico. As matérias examinadas estão quase sempre acompanhadas por argumentos relacionados à questão da cidadania e à necessidade de se alcançá-la na sociedade, destacando a condição marginal do trabalho de imigrantes haitianos, mas resistindo em representá-los como indivíduos portadores de capacidades produtivas. Essas ênfases deixam de problematizar outras questões pertinentes sobre os imigrantes, como, por exemplo, a discussão da Política e do Plano Nacional sobre Migração e Refúgio. Da mesma forma, a inserção de questões do trabalho em uma discussão sobre cidadania demonstra também a centralidade desse tema - de várias características, mas, sobretudo, econômica - em um espaço que poderia estar vinculado a outras questões.

A matéria "Haitianos optam por rota clandestina" (HAITIANOS..., 2014, p. 5) associa os imigrantes ao tema da clandestinidade. 0 jornal traçou um perfil sobre os haitianos e destacou que o Paraná, na época, contava com mais de 4 mil deles. Entretanto, o conteúdo conduz o leitor para uma interpretação apenas genérica do fenômeno da migração, como explicita o trecho: "O grande índice de clandestinos e a própria dinâmica de migração e fixação dificultam a consolidação de registros oficiais." (HAITIANOS..., 2014, p. 5). A fotografia utilizada, que traz oito negros haitianos, dentre eles uma mulher e três crianças, não se comunica com o título. $\mathrm{Na}$ imagem em questão, evidencia-se a relação haitianos/emprego, com cinco imigrantes sentados, de forma displicente e até "largada”, em uma escadaria. Seria esta a intenção subjacente ao discurso? 
Outra observação a se considerar é que o jornal não escolhe uma fonte direta entre os imigrantes para elucidar a notícia, mas convoca uma representante da ONG Casa LatinoAmericana (Casla), de Curitiba, para tratar o assunto. Entretanto, é nesta matéria que aparece a primeira referência à abordagem de "cultura", expressa na voz da presidente da comissão da OAB: "Tem aquele pensamento de que o migrante vai tirar emprego de quem nasceu aqui. É uma besteira. 0 migrante vem contribuir, colaborar com a sociedade e contribuir com a cultura local. ". (HAITIANOS..., 2014, p. 5)

A característica principal destas 13 matérias com abordagem predominantemente econômica, no entanto, é o distanciamento do discurso entre o indivíduo que pratica a ação de saída e entrada em outro país, do mesmo indivíduo que pede refúgio neste país, bem como da necessidade de políticas sociais para que valores básicos como moradia e alimentação não faltem. A fala do especialista e de políticos, especialmente marcada na matéria - "Secretário diz que haitianos estão sendo 'despejados' na cidade” (SECRETÁRIO..., 2014, p. 9) - joga o imigrante para o campo da desterritorialização, em um processo marcado pela falta de integração, que remete à alienação em tempos de mobilidade global.

De janeiro a junho de 2014, a Gazeta do Povo produziu para a editoria Vida e Cidadania três reportagens locais sobre os haitianos: 1) "Curitiba: terra de paz para o recomeço" (ANÍBAL, 2014, p. 4); 2) “Um crime que insiste em se repetir" (ANÍBAL, 2014b, p. 4) e 3) "Haitianos comemoram o Dia da Bandeira com festas no Paraná" (CRUZ, 2014, p. 11). Seguem abaixo as análises das três matérias consideradas ${ }^{5}$.

"Curitiba: terra de paz para o recomeço" apresenta abaixo do título a palavra "Refugiados" e inclui os haitianos entre outros imigrantes que vivem em Curitiba. A matéria cita que há "[...] um fluxo migratório intenso de africanos (principalmente da Nigéria, Congo e GuinéBissau) e da América Latina, muitas vezes atraídos pelo sonho de um emprego" (ANÍBAL, 2014, p. 4), e dá voz aos sírios e equatorianos, à Pastoral do Migrante e novamente ouve a Casla como fonte. Em relação às fotos, na versão impressa utilizou-se a imagem de uma família síria. Na versão online, a galeria com 16 fotos desses dois grupos retrata cenas com a família, crianças e adultos com indumentárias típicas e demais cenas cotidianas. A abordagem cultural foi explicitada pela personagem equatoriana: "Meus pais me ensinaram a valorizar minha cul-

${ }^{3}$ Os textos das colunas "Entrelinhas" (dentro da editoria Vida e Cidadania) não foram analisados por serem opinativos. 
tura. Gostamos muito do Brasil, mas nunca vamos nos esquecer de quem somos". (ANÍBAL, 2014, p. 4). A outra referência aos haitianos está no box "Falta de dados emperra políticas públicas", onde a imigração está associada à irregularidade jurídica: "A OAB calcula que o Paraná tenha hoje cerca de 50 mil estrangeiros vivendo legalmente - 19 mil em Curitiba. Outros cinco mil - principalmente haitianos e andinos - devem estar irregularmente no estado." (ANÍBAL, 2014, p. 4).

A reportagem "Um crime que insiste em se repetir" abre com o relato do haitiano Stanley Joseph, de 27 anos, radicado em Curitiba: “'Saia daqui, seu macaco preto' [...] As ofensas racistas que recebeu [...] foram gritadas pela dona de uma agência, onde ele procurava uma vaga de emprego. Antes fosse uma exceção, mas casos como os de Joseph beiram o corriqueiro." (ANÍBAL, 2014b, p. 4) A matéria traz ainda a declaração do senador Paulo Paim (PT), autor do projeto de lei (PL 6.418/05) que propõe o endurecimento contra quem cometer preconceito por cor, etnia, religião ou origem. Também ouve o advogado e militante do movimento negro, Antonio Leandro da Silva, que discorreu sobre a aplicação da lei em crimes de racismo, e o presidente do Instituto Brasil e África, Saul Dorval da Silva, que destacou a necessidade de políticas específicas voltadas aos negros. Outra fonte utilizada foi o Centro Integrado de Atendimento ao Cidadão (Ciac), local onde Joseph registrou boletim de ocorrência do caso. Novamente são ouvidas como fontes a Comissão de Direitos dos Migrantes da OAB e da Casla, que intercederam pelos haitianos neste caso específico. Apesar de não haver referência ao termo "cultura", o rosto de Joseph, que estampa a fotografia da matéria também na capa do jornal, por si só evidencia a cor da pele e a consequência disso sobre as subjetividades de sua situação de imigrante e de vítima do racismo, uma questão eminentemente cultural.

Na última matéria local, "Haitianos comemoram o Dia da Bandeira com festas no Paraná", evidencia-se o interesse em explorar um pouco da cultura daquele país. 0 jornal preocupou-se em resgatar o histórico da comemoração do Dia da Bandeira do Haiti em Curitiba e em Cascavel, PR: "Na capital, integrantes da comunidade haitiana se reuniram ontem no Memorial de Curitiba. 0 evento marcou 211 anos da independência do país com apresentações musicais, gastronomia e atividades de integração." (CRUZ, 2014, p. 11). 0 termo cultura foi evidenciado pelo haitiano Joe Celintery, coordenador da Associação de Defesa dos Imigrantes Haitianos criada em maio de 2014, em Cascavel, PR -, quando ele explicou que o Dia da Bandeira é um 
feriado em seu país, no qual acontecem festas, conferências e apresentações com música e danças típicas. "É um ato que tem o objetivo de manter nossas tradições e cultura vivas." (CRUZ, 2014, p. 11). Na mesma reportagem ainda foi citada a Associação dos Haitianos de Curitiba e a Casla. 0 apoio da Fundação Cultural de Curitiba (FCC) ao evento, citado no texto, mostra que o poder público, na área cultural, já observou a presença dos estrangeiros.

De forma geral, a análise das três reportagens locais indica que, nas abordagens escolhidas (subtemas) para o tema principal, os imigrantes haitianos aparecem dizendo muito pouco sobre a cultura de seu país e sobre o seu modo de vida. Como já mencionado, os antecedentes de sua vinda para o Brasil não são explorados. A partir da leitura analítica dessas matérias é possível afirmar que a representação feita pelo jornal em relação aos haitianos é diferenciada da feita em relação aos demais imigrantes. Os haitianos, na maioria das vezes, não têm voz direta e estão relacionados à questão do mercado de trabalho, ao preconceito sofrido, às relações com as agências de emprego, condições de vida e moradia, dentre outros.

No entanto, vale ressaltar que, no mês de maio, o Caderno $G$ do mesmo jornal deu espaço a uma atividade cultural relacionada ao povo haitiano, já que se trata de um caderno de cobertura cultural. A matéria "Ciclo de Leituras de Literatura Haitiana termina amanhã" (CICLO..., 2014, p. 3) comenta sobre o evento promovido pela Fundação Cultural de Curitiba com o objetivo de fazer o "movimento de integração Brasil-Haiti" (CICLO..., 2014, p. 3). Em junho, a reportagem "Para ouvir o Haiti” (COSTA, 2014, p. 5), no Caderno G, trouxe uma página completa sobre jovens músicos do Haiti que fundaram o grupo musical Recif, dando-lhes visibilidade por meio da fotografia utilizada e pela disponibilização de vídeo do grupo na versão online do jornal. Um colunista também fez referência aos haitianos que trabalharam na reforma da Arena da Baixada, estádio que sediaria os jogos da Copa 2014, ao afirmar "Sorte esses bravos caribenhos terem sete vidas: enfrentaram o terremoto, o furacão, a cólera, a fuga para o Acre, o clima de Curitiba e, agora, a construção da Torre de Babel." (FERNANDES, 2014, p. 6), mostrando, em breves palavras - cronologicamente -, as dificuldades pelas quais os imigrantes haitianos passaram.

Ao notar a ausência de notícias sobre haitianos no encarte de cultura, é possível perceber que, embora o jornal obstrua a importância da cultura migrante representada pela riqueza das artes, crenças e símbolos, o mesmo confere ao povo haitiano uma identidade, neste 
caso, relacionada ao trabalho e à busca por melhores condições de vida. Neste sentido, o ser cultural acaba sendo observado por esta nuance à medida que o trabalho assalariado possibilita a inserção do haitiano na sociedade e um vínculo com o Haiti, oferecendo oportunidade para a reconstrução econômica do país por intermédio do envio de remessas do dinheiro advindo do trabalho.

Em contrapartida, a compreensão sobre o reconhecimento do ser cultural é prejudicada pela distância que há entre a territorialização do imigrante no novo espaço - como condição de conquista de cidadania (SANTOS, 2012) - e a própria cidadania. A dificuldade com o trabalho e o preconceito, temas importantes que surgiram durante a análise, demonstram, através da cobertura midiática, a ainda quase inexistente conquista da cidadania, visto que o trabalho caracterizado como processo intrinsecamente econômico é o viés que ocupa espaços importantes no jornal.

\section{Considerações finais}

No campo das práticas jornalísticas, com relação aos imigrantes haitianos, a mídia brasileira vem dando destaque à situação desde 2011. No Paraná, as notícias reproduzidas de agências nacionais pela Gazeta do Povo procuram enfatizar esse recente fenômeno como um problema. É perceptível o uso de termos como "irregulares", "clandestinos", "refugiados", o que também corresponde à parte da realidade social deste grupo; por outro lado, as matérias, em especial aquelas produzidas localmente, evidenciam a existência de redes e organizações de apoio aos imigrantes.

O que essa contradição entre local e nacional esconde no caso de matérias publicadas sobre os haitianos? Será talvez uma irrefletida compreensão dos próprios conceitos de imigração ou será que há uma intenção que alimenta a representação desses povos? Para responder a esses questionamentos, é preciso entender o processo da imigração como tematização tratada pela mídia nacional ou pelos jornais locais nos municípios onde tais imigrantes estão instalados.

A pesquisa permitiu verificar que as matérias do jornal Gazeta do Povo apresentam dificuldade em mostrar o haitiano como um ser cultural, cuja identidade seria marcada pelas tentativas iniciais de hibridização com a cultura receptora, transformando-a. Oposto a isso, foi 
mais notável a publicização da ideia de uma "invasão" cultural pelo grande número de imigrantes chegando ao país. Neste sentido, foi possível identificar o haitiano pelo viés do trabalho e da busca por melhores condições de vida, processos nos quais o sujeito imigrante encontra problemas de relacionamento, como o preconceito, e problemas legais, como a dificuldade na aquisição de documentos e de direitos. A dimensão do trabalho, como suposto inicialmente, não demonstra, por ora, a conquista da cidadania pelos haitianos, focando muito mais o preconceito e a impossibilidade de condições dignas de vida. Neste sentido, ver o trabalho menos pelo viés econômico e mais pelo viés da cidadania, seria uma contribuição a um novo modelo cívico, como sinaliza Santos (2012):

Todo nosso esforço deve estar empenhado na codificação desse modelo cívico, não mais subordinado ao modelo econômico, como até agora se deu, mas com um modelo cívico que oriente a ação política e alicerce a solidariedade social, e ao qual o modelo econômico e todos demais modelos sejam subordinados. (SANTOS, 2012, p. 126).

A análise realizada nos leva a afirmar que a Gazeta do Povo cumpre uma função de "reagendamento" do tema ao reproduzir notícias de agências noticiosas (FolhaPress, Agência Estado, $O$ Globo), mas mostrou que também produz reportagens específicas sobre estes imigrantes, por meio de vieses mais amplos e positivos, ainda que não realize uma comunicação efetiva com a comunidade haitiana. É preciso aproximar os imigrantes da condição de fala nas matérias jornalísticas para que se evite o reforço de estereótipos, seja pelo reforço do boliviano associado ao trabalho escravo ou mão de obra barata, ou pelo africano e o haitiano, lembrados apenas por sua cor de pele e diferenças de idiomas.

No Paraná, a ONG Casa Latino-Americana, instituição sem fins lucrativos, fundada em 1985 e que discute as questões da América Latina por meio de ações educacionais e culturais, é uma referência no caso de auxílio a imigrantes e refugiados. A entidade oferece assessoria jurídica com o objetivo de regularizar a situação dos haitianos e, por conseguinte, para que busquem oportunidades no mercado de trabalho, tornando-se, assim, uma rede social informal para esses sujeitos, uma vez o trabalho em rede surge sob as demandas das subjetividades, das necessidades e das identidades. Nesse sentido, por meio dessas redes de mediação, é possível a interlocução de vozes que não ressoam em outros lugares. 
O que podemos afirmar é que todos os migrantes são portadores e sujeitos de heterogeneidade cultural e, portanto, acabam por interferir/se integrar em uma cultura mesmo fora de seu território. No entanto, é importante que eles possam dar novos significados ao novo ambiente. Nesta pesquisa, percebe-se que os haitianos já estão articulados em redes institucionais em Curitiba: representações como a Pastoral do Migrante, a Casla, o movimento negro local e os diferentes grupos nas redes sociais ouvidos como fontes nas matérias analisadas mostram que a comunicação e o diálogo no novo território são possíveis, pois essas redes se configuram como espaços nos quais se efetiva a comunicação e, por conseguinte, a interação.

Ao se considerar que vivemos em um intenso processo global de deslocamentos de pessoas, o papel da mídia jornalística, além de ouvir as redes e organizações de apoio aos imigrantes, seria também o de dar voz aos sujeitos que escolheram esse país para recomeçar suas vidas, dando-lhes visibilidade cultural e cidadã, para que se evitem preconceitos sobre o outro, que desestabilizam e segregam.

\section{Referências}

ACORDO dá conta bancária para haitianos em SP. Gazeta do Povo. Curitiba. 12 mai. 2014. Vida e Cidadania, p. 7.

ANÍBAL, Felippe. Curitiba: terra de paz para recomeço. Gazeta do Povo. Curitiba. 16 fev. 2014. Vida e Cidadania, p.4.

ANÍBAL, Felippe. Um crime que insiste em se repetir. Gazeta do Povo. Curitiba. 10 mar. 2014b. Vida e Cidadania, p.4.

ALSINA, Miquel. A construção da notícia. Petrópolis: Vozes, 2009.

BHABHA, Homi. O local da cultura. Belo Horizonte: UFMG, 1998.

BOURDIEU, Pierre. Outline of a theory of practice. Cambridge: Cambridge University Press, 1977.

BOURDIEU, Pierre. Homo academicus. Paris: Minuit, 1984

BOURDIEU, Pierre; PASSERON, Jean Claude. Reproduction in education, society and culture. Beverly Hills: Sage, 1977. 
CANCLÍNI, Néstor García. Culturas híbridas: estratégias para entrar e sair da modernidade. São Paulo: Edusp, 2013.

CARDOSO, Camille; SENKOVSKI, Antonio. Haitianos reclamam direitos trabalhistas. Gazeta do Povo. Curitiba. 13 mar. 2014. Economia. p. 21.

CARDOZO, José Eduardo; PATRIOTA, Antonio de Aguiar. Brasil e Haiti: parceria para o desenvolvimento. Folha de São Paulo, 15 jan. 2012. Opinião. Disponível em: $<$ http://www1.folha.uol.com.br/fsp/opiniao/20185-brasil-e-haiti-parceria-para-odesenvolvimento.shtml >. Acesso em: 10 julho de 2014.

CICLO de leituras de literatura haitiana termina amanhã. Gazeta do Povo. Curitiba. 25 mai. 2014. Caderno G, p. 3.

COGO, Denise. Comunicação cidadã sob o enfoque transnacional. Revista Brasileira de Ciências da Comunicação, São Paulo, v. 33, n. 1, p. 81-103, jan./jun. 2010.

COGO, Denise. Haitianos no Brasil: comunicação e interação em redes migratórias transnacionais. Revista Chasqui. Quito, n. 125, p. 23-32, mar. 2014.

COGO, Denise. Mídia, migração e interculturalidade: mapeando as estratégias de midiatização dos processos migratórios e das falas imigrantes do contexto brasileiro. Revista Comunicação e Informação, Goiânia, v. 4, n. 1/2, p. 11-32, jan./dez. 2001.

COGO, Denise; BADET, Maria. De braços abertos... a construção midiática da imigração qualificada e do Brasil como país de imigração. In: ARAÚJO, Emília; FONTES, Margarida; BENTO, Sofis (Org.). Para um debate sobre mobilidade e fuga de cérebros. Braga: Centro de Estudos de Comunicação e Sociedade, Universidade do Minho, 2013. p. 32-57.

COSTA, Rafael Rodrigues. Para ouvir o Haiti. Gazeta do Povo. Curitiba. 22 jun. 2014. Caderno G, p. 5.

CRUZ, Luiz Carlos da. Haitianos comemoram o Dia da Bandeira com festas do Paraná. Gazeta do Povo. Curitiba. 19 mai. 2014. Vida e Cidadania, p. 11.

ELHAJJI, Mohammed. Migrações, TICs e comunidades tradicionais: o devir diaspórico na era global. In: CONGRESSO BRASILEIRO DE CIÊNCIAS DA COMUNICAÇÃO, 34. Anais... Recife, 2011.

EM SITUAÇÃO precária, haitianos “lotam” o Acre. Gazeta do Povo. Curitiba, 17 jan. 2014. Vida e Cidadania, p. 8.

FERNANDES, José Carlos. 0 time do veneno. Gazeta do Povo. Curitiba, 10 jun. 2014. Caderno Especial Copa, p. 6. 
HAITIANOS optam por rota clandestina. Gazeta do Povo. Curitiba. 18 fev. 2014, p. 5.

HALL, Stuart. Da diáspora: identidade e mediações culturais. Belo Horizonte: UFMG, 2012.

HERSCOVITZ, Heloiza Golbspan. Análise de conteúdo em jornalismo. In: LAGO, Claudia; BENETTI, Marcia. (Org.) Metodologia de Pesquisa em Jornalismo. Petropólis: Vozes, 2008.

LACHINI, André. Grande São Paulo pode ter até 500 mil bolivianos. Gazeta do Povo. Curitiba. 17 fev. 2014. Vida e Cidadania, p. 7.

MAAKAROUN, Bertha; AUGUSTO; Leonardo. Brasil terá 50 mil imigrantes até o final do ano. Estado de Minas. 17 mai. 2014. Política. Disponível em:

<http://haitianosbrasil.blogspot.com.br/search?q=brasil+ter\%C3\%A1+50>. Acesso em: 20 agosto de 2014 .

MAIGRET, Éric. Sociologia da comunicação e das mídias. São Paulo: Senac, 2010.

MARINS, Lucas. 2 mil haitianos vivem "sonho curitibano". Gazeta do Povo. 28 dez. 2013. Trabalho. Disponível em: <http://www.gazetadopovo.com.br/economia/2-mil-haitianosvivem-sonho-curitibano-9eej1gowl4ytsphn772ph8y1a>. Acessado em: 20 agosto de 2014.

NÚMERO de deslocados forçados ultrapassa 50 milhões pela primeira vez desde a Segunda Guerra Mundial. ONU Brasil. 20 jun. 2014. Disponível em:

$<$ https://nacoesunidas.org/numero-de-deslocados-forcados-ultrapassa-50-milhoes-pelaprimeira-vez-desde-a-segunda-guerra-mundial/>. Acessado em: 25 agosto de 2014.

PEDIDOS de refúgio ao Brasil crescem quase dez vezes. Gazeta do Povo. Curitiba, 15 mai. 2014. Vida e Cidadania, p. 5.

SANTOS, Milton. 0 espaço do cidadão. 7. ed. São Paulo: Edusp, 2012.

SÃO PAULO monta plano emergencial para atender haitianos. Gazeta do Povo. Curitiba, 26 abr. 2014. Vida e Cidadania, p. 4.

SECRETÁRIO diz que haitianos estão sendo 'despejados' na cidade. Gazeta do Povo. Curitiba, 29 abr. 2014. Vida e Cidadania, p. 9.

SILVERSTONE, Roger. Por que estudar a mídia? São Paulo: Loyola, 2005.

SINE de Curitiba é porta de entrada para haitianos no mercado de trabalho. Prefeitura de Curitiba. 10 nov. 2014. Trabalho e Emprego. Disponível em:

<http://www.curitiba.pr.gov.br/noticias/sine-curitiba-e-porta-de-entrada-para-haitianos-nomercado-de-trabalho/34671>. Acessado em: 21 jan. 2015.

VAN DIJK, Teun A. Discurso e poder. 2. ed. São Paulo: Contexto, 2012. 
VAN DIJK, Teun A. (Org.). Racismo e discurso na América Latina. São Paulo: Contexto, 2008.

\title{
Aspects of the representation of Haitian im- migrants in the newspaper Gazeta do Povo, from Curitiba/PR
}

\begin{abstract}
Since the 2010 earthquake in Haiti, a steady stream of immigration of inhabitants from that country to Brazil began. This article considers the survey and analysis of material published by the newspaper Gazeta do Povo, in Curitiba, PR, on the immigration of Haitians in the first half of 2014. The choice of theme is justified by the considerable number of these immigrants in Curitiba, as well as by the implications and contributions the research can offer to the communication area in front of a global immigration scenario. The work reflected on the problems of migration, on the identity of the groups involved and on the communication in the sphere of a migration scenario. The paper assumes that the media press still has a key role in democratic societies and that it does not emphasize the immigrant as a cultural being, but prioritizes the economic bias. Empirically, a content analysis of published materials was realized to understand the representation built on Haitians in the newspaper.
\end{abstract}

\section{Keywords}

Communication and migration. Migration of Haitians. Culture and citizenship. Newspaper Gazeta do Povo.

Recebido em 15/05/2015

Aceito em 03/12/2015 